\title{
Individual- and Household-Level Interventions to Reduce Air Pollution Exposures and Health Risks: a Review of the Recent Literature
}

\author{
Ryan W. Allen ${ }^{1} \cdot$ Prabjit Barn ${ }^{2}$ \\ Accepted: 4 November 2020 / Published online: 26 November 2020 \\ (C) The Author(s) 2020
}

\begin{abstract}
Purpose of Review We reviewed recent peer-reviewed literature on three categories of individual- and household-level interventions against air pollution: air purifiers, facemasks, and behavior change.

Recent Findings High-efficiency particulate air/arresting (HEPA) filter air purifier use over days to weeks can substantially reduce fine particulate matter $\left(\mathrm{PM}_{2.5}\right)$ concentrations indoors and improve subclinical cardiopulmonary health. Modeling studies suggest that the population-level benefits of HEPA filter air purification would often exceed costs. Well-fitting N95 and equivalent respirators can reduce $\mathrm{PM}_{2.5}$ exposure, with several randomized crossover studies also reporting improvements in subclinical cardiovascular health. The health benefits of other types of face coverings have not been tested and their effectiveness in reducing exposure is highly variable, depends largely on fit, and is unrelated to cost. Behavior modifications may reduce exposure, but there has been little research on health impacts.

Summary There is now substantial evidence that HEPA filter air purifiers reduce indoor $\mathrm{PM}_{2.5}$ concentrations and improve subclinical health indicators. As a result, their use is being recommended by a growing number of government and public health organizations. Several studies have also reported subclinical cardiovascular health benefits from well-fitting respirators, while evidence of health benefits from other types of facemasks and behavior changes remains very limited. In situations when emissions cannot be controlled at the source, such as during forest fires, individual- or household-level interventions may be the primary option. In most cases, however, such interventions should be supplemental to emission reduction efforts that benefit entire communities.
\end{abstract}

Keywords PM2.5 $\cdot$ Smoke $\cdot$ Traffic $\cdot$ Intervention $\cdot$ Randomized $\cdot$ Crossover $\cdot$ HEPA $\cdot$ Mask $\cdot$ N95 $\cdot$ Respirator

\section{Introduction}

Air quality improvements in wealthy countries have improved public health [1-4]. Global progress toward clean air, however, has been uneven. More than $90 \%$ of the world's population breathes fine particulate matter $\left(\mathrm{PM}_{2.5}\right)$ above the World Health Organization's (WHO) guideline concentration and

This article is part of the Topical Collection on Air Pollution and Health

Ryan W. Allen

allenr@sfu.ca

1 Faculty of Health Sciences, Simon Fraser University, Burnaby, BC, Canada

2 Legacy for Airway Health, Vancouver Coastal Health, Vancouver, BC, Canada air pollution remains a leading cause of disease and premature death [1]. Even low concentrations pose a threat because there appears to be no safe exposure threshold [5-7].

It will be decades before the global health impacts of air pollution can be reduced to acceptable levels [8]. For example, between 2013 and 2017, China's ambitious Air Pollution Prevention and Control Action Plan reduced $\mathrm{PM}_{2.5}$ concentrations by $33 \%$ across 74 cities [9-11]. But following that extraordinary improvement, the average $\mathrm{PM}_{2.5}$ concentration in those cities was $47 \mu \mathrm{g} / \mathrm{m}^{3}$ - or nearly five times the WHO guideline concentration [10]. We have worked for several years in Ulaanbaatar, Mongolia, a city with notoriously polluted air [12-16]. Piecemeal efforts by the government and international organizations to reduce pollution have had little impact, and citizens have protested and demanded that more be done [17]. Clearing the air will require radical changes to the city's energy supply and infrastructure, so even under 
optimistic scenarios Ulaanbaatar's air will threaten public health for many years to come [18].

Given the slow pace of progress in many settings, individuals struggle to protect themselves and their communities [19-21]. A private campaign in Ulaanbaatar raised approximately $\$ 40,000$ (US) in financial and in-kind support to distribute air purifiers to children's hospital wards [22], and we frequently hear stories of families sending children to schools abroad to escape the pollution. Similarly, some wealthy "pollution refugees" are leaving other highly polluted cities like New Delhi for places with cleaner air [23].

Some individual- and household-level (IHL) interventions are now big business, although the marketing claims often exaggerate the scientific evidence [24-26]. One can purchase "DIY" air purifiers kits [27], air filtering baby pillows are being developed [28], and facemasks appear at fashion shows [29]. During a particularly polluted period in New Delhi, officials announced plans to distribute five million facemasks to schoolchildren [30]. One study estimated that a day of "severe" pollution in eight Chinese megacities leads to $\$ 200,000$ (US) in facemask sales [31]. Another study estimated that a $10 \%$ reduction in the number of "heavily polluted" days across China over a 16-month period would reduce facemask sales by $\$ 187$ million (US) [32].

IHL interventions represent a "Band Aid" solution and are not a viable long-term alternative to emissions reductions. But some of these interventions may have value - particularly in high pollution settings, for vulnerable individuals, and/or when emissions cannot be managed at the source.

Interest in these interventions among researchers continues to grow. Several reviews and commentaries have been published in recent years [33-42], with most discussing one class of interventions [36•], a narrow range of health outcomes [37, 41], a specific pollution source [42], and/or specifically targeting clinicians [38-41]. We sought to broadly summarize the most important recent research findings for three categories of interventions: air purifiers, facemasks, and behavior modifications. Our goal was not to conduct a systematic review, but rather to identify contemporary research themes and areas of overlap, offer suggestions for future studies, and share some thoughts based on our own research experiences in this area.

We searched the PubMed and Web of Science databases by combining search terms related to air pollution (e.g., particulate matter, $\mathrm{PM}_{2,5}$, smoke) with terms related to our three categories of interventions (e.g., HEPA, mask, windows). We reviewed the abstracts identified by these searches, selected relevant articles, and then performed reference and citation searches on them. We were primarily interested in intervention studies targeting $\mathrm{PM}_{2.5}$, the pollutant most consistently linked with health outcomes, and studies published in 2017 or later (although some particularly relevant older studies are discussed). Interventions targeting air pollution from cooking and/or heating stoves are outside our scope and are discussed elsewhere [43, 44].

\section{Air Purifiers}

People spend most of their time indoors [45]. Because outdoor air pollution infiltrates into buildings, "indoor air" contains both indoor- and outdoor-generated pollution [46]. Indoor exposures account for $61 \%$ and $81 \%$ of the deaths attributed to outdoor-generated $\mathrm{PM}_{2.5}$ in the USA and China, respectively $[47,48]$. Thus, reducing $\mathrm{PM}_{2.5}$ indoors may also mitigate the impacts of outdoor-generated particles.

Indoors, particles can be removed by placing air purifiers in a building's heating, ventilation, and air conditioning (HVAC) system or by using portable, stand-alone air purifiers. Most studies have focused on mechanical filtration with highefficiency particulate air/arresting (HEPA) filters, which remove at least $99.97 \%$ of $0.3 \mu \mathrm{m}$ particles. Fewer studies have evaluated other technologies such as electrostatic precipitators (EPs) or negative ion generators (IGs), both of which produce ions that attach to particles and promote deposition. Two factors govern air purifier effectiveness: the efficiency of the device at removing pollution and the volume of air brought through the device. Two rating systems are commonly used to evaluate air purifiers. HVAC filters are given a minimum efficiency reporting value (MERV) between 1 and 16, while portable air purifiers are often described by the clean air delivery rate (CADR). More details on air purification technologies were provided in a recent review [36॰].

By 2017, there was substantial evidence from randomized studies in North America and Europe that HEPA filtrationeither in HVAC systems or with portable units - can reduce $\mathrm{PM}_{2.5}$ concentrations by $50 \%$ or more over periods of a few days to 2 weeks [36•]. Several studies also reported improvements in subclinical cardiovascular health indicators including systolic blood pressure [49], endothelial function [50, 51], and systemic inflammation [51, 52]. Our review identified four main themes in recent research: (1) evaluations of exposure and health impacts from air filtration in highly polluted settings and over longer durations, (2) studies of personal exposure impacts from filtration, (3) cost-benefit analyses of filtration, and (4) investigations involving EPs and IGs (Table 1).

Three recent studies in China demonstrated large concentration reductions from air filtration in highly polluted settings. In Beijing, portable HEPA filter air purifier use for 2 weeks reduced $\mathrm{PM}_{2.5}$ concentrations from 60 to $24 \mu \mathrm{g} / \mathrm{m}^{3}$ in the homes of non-smoking seniors $[53,54]$. The air purifiers also reduced systemic inflammation, but did not affect lung function, blood pressure, or heart rate variability (HRV) [53]. In a suburb of Shanghai, $13 \mathrm{~h}$ of portable HEPA filtration reduced mean indoor $\mathrm{PM}_{2.5}$ concentrations from 33 to $10 \mu \mathrm{g} / \mathrm{m}^{3}$ in the homes of non-smoking young adults [55]. Filtration was 


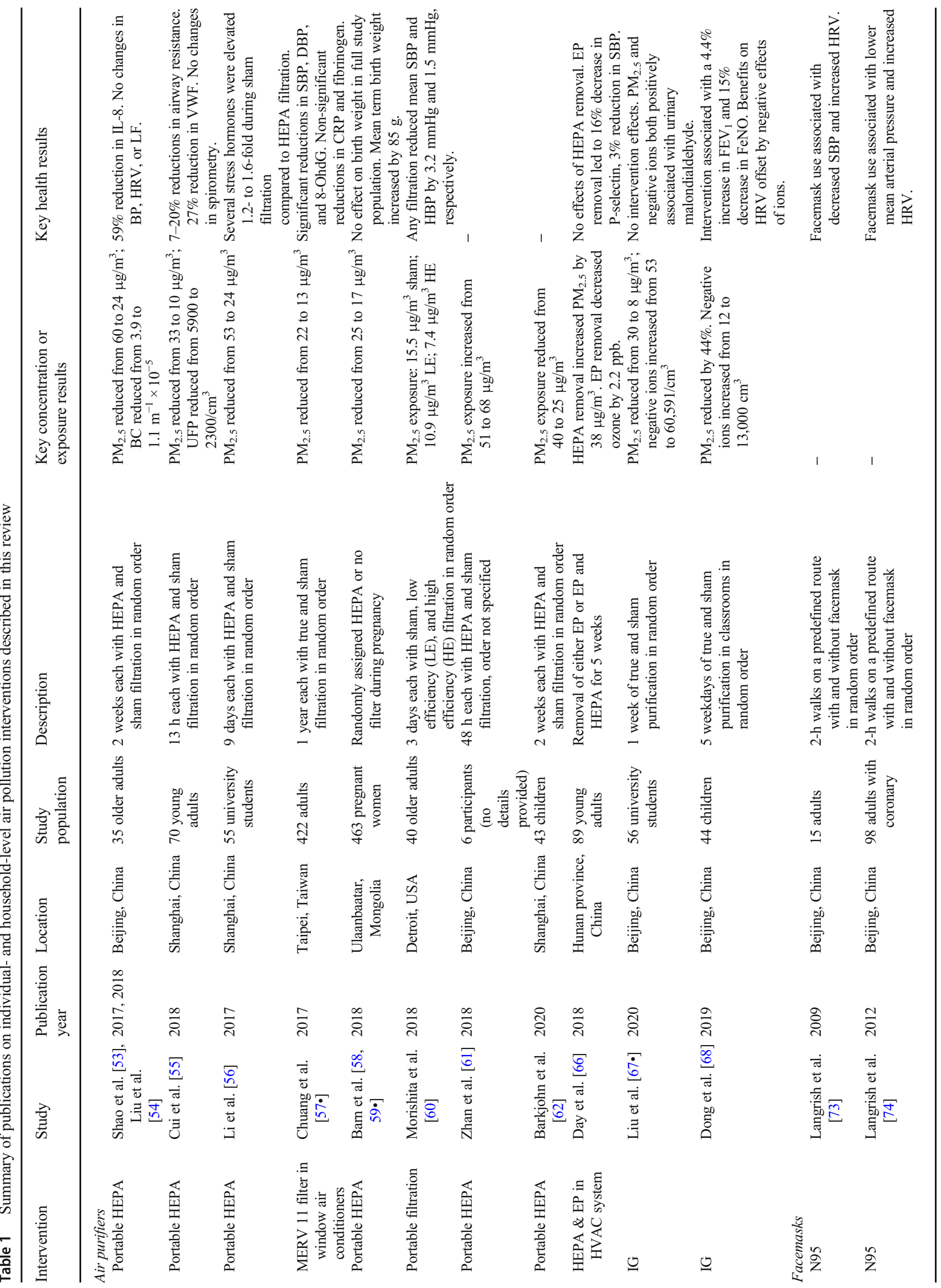




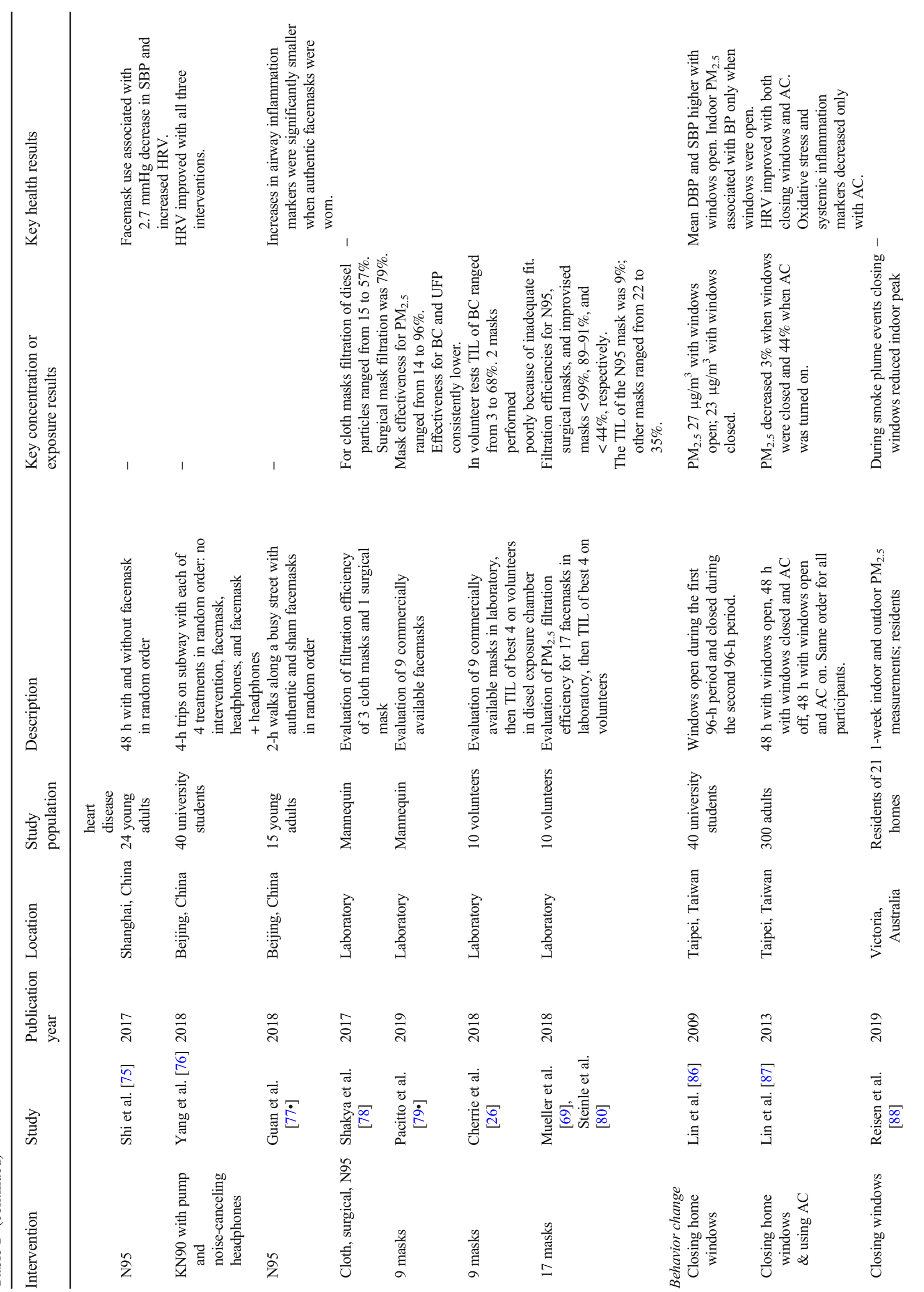




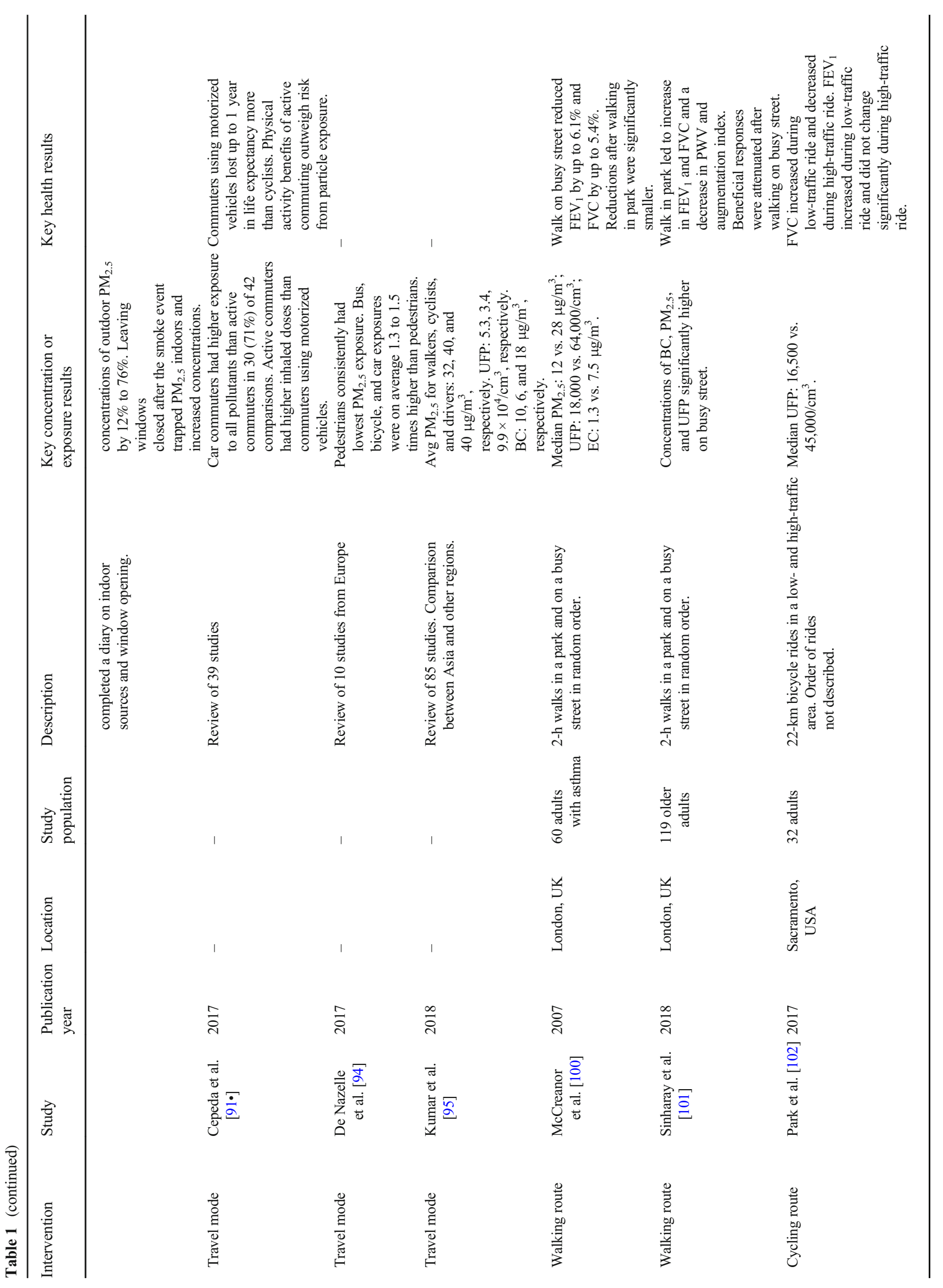




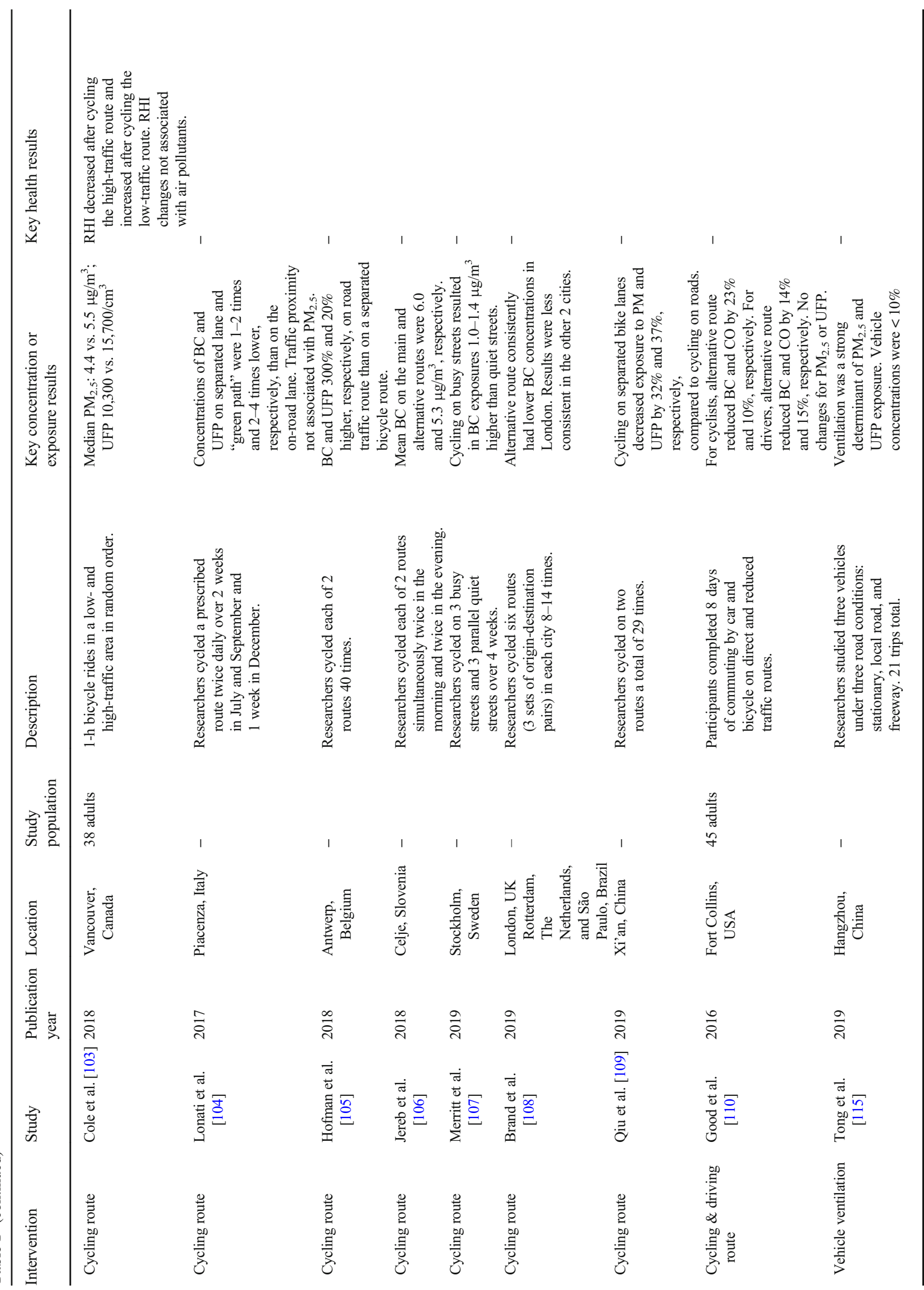




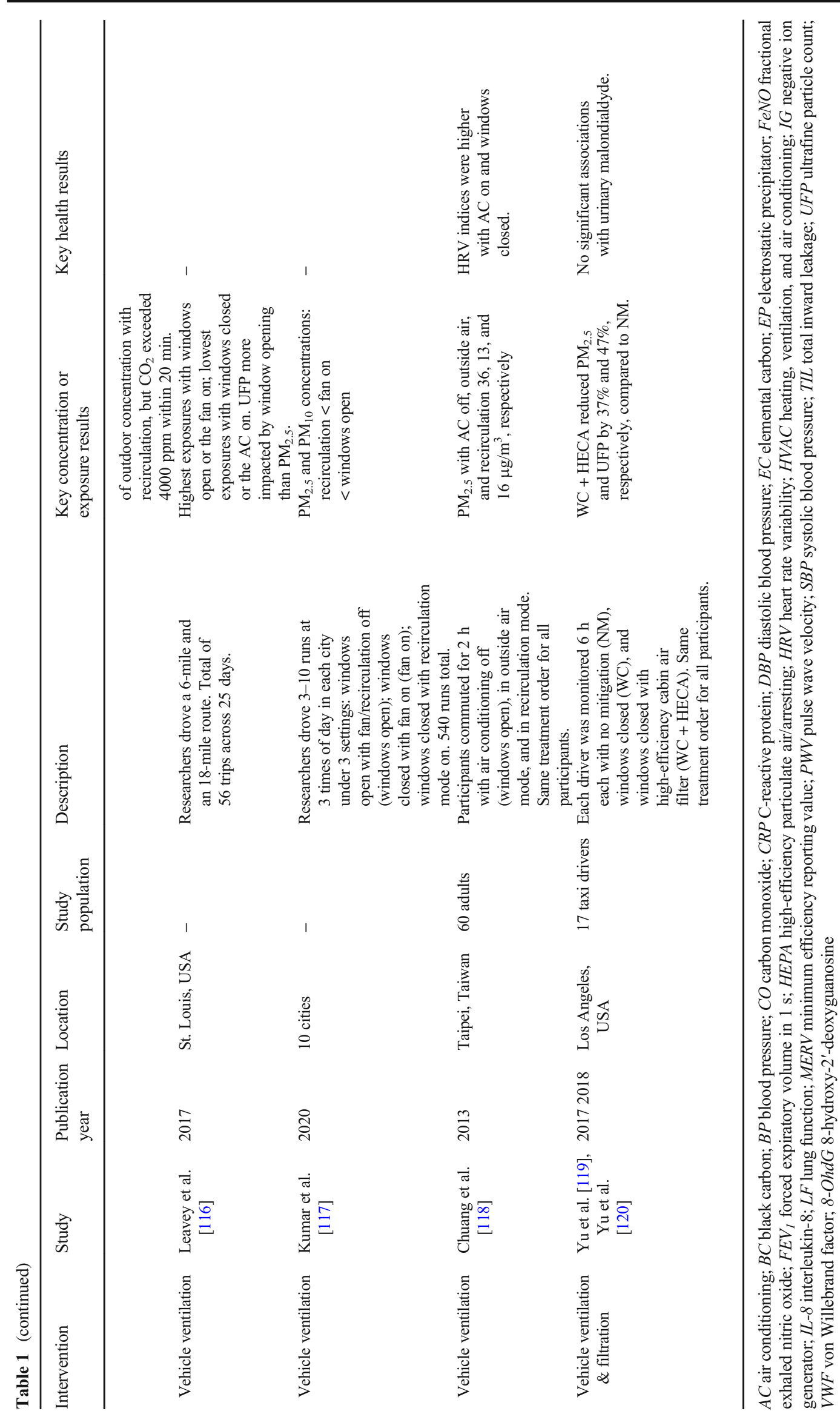


associated with improved airway mechanics and reduced thrombosis risk, with no improvements in spirometry or airway inflammation - and a small, marginally significant increase in diastolic blood pressure. In a study of young adults in Shanghai, use of portable air filters over 9 days reduced average $\mathrm{PM}_{2.5}$ concentrations in dormitories from 47 to $9 \mu \mathrm{g} / \mathrm{m}^{3}$, while also reducing stress hormones and improving indicators of blood pressure, insulin resistance, oxidative stress, and inflammation [56].

Two recent studies evaluated air purifier efficacy over relatively long durations. Chuang and colleagues [57•] enrolled 200 homemakers in Taipei into a study of MERV 11 filtration in window air conditioning units. Participants were randomly assigned to a filtration intervention or sham control group for 1 year, and then to the opposite group for the second year. Filters reduced indoor $\mathrm{PM}_{2.5}$ concentrations from 22 to $13 \mu \mathrm{g} /$ $\mathrm{m}^{3}$ and were associated with reductions in blood pressure, systemic inflammation, and oxidative stress. Our Ulaanbaatar Gestation and Air Pollution Research (UGAAR) study is a randomized controlled trial designed to evaluate the impacts of portable HEPA filter air purifier use during pregnancy on fetal growth and childhood development [58, 59]. Air purifiers reduced indoor $\mathrm{PM}_{2.5}$ concentrations during pregnancy by $29 \%$ (from 25 to $17 \mu \mathrm{g} / \mathrm{m}^{3}$ ), with greater $\mathrm{PM}_{2.5}$ reductions in colder months. In addition, effectiveness was greater when air purifiers were first deployed (40\% reduction) than after approximately 5 months of use (15\% reduction). Overall, participants reported using air purifiers for $64 \%$ of the study period. The intervention led to an $85 \mathrm{~g}$ (95\% CI: 3, $167 \mathrm{~g}$ ) increase in mean term birth weight.

Three recent studies suggested that air filters have less impact on personal exposures than on indoor concentrations. In Detroit, Morishita and colleagues [60] measured $\mathrm{PM}_{2.5}$ exposure and blood pressure changes among 40 non-smoking participants in a low-income senior residential facility. Air purifiers, which were placed in participants' bedrooms and living rooms, reduced indoor $\mathrm{PM}_{2.5}$ concentrations by $52 \%$ with low efficiency filtration and by $59 \%$ with HEPA filtration. Personal $\mathrm{PM}_{2.5}$ exposure reductions were smaller: $30 \%$ with low efficiency filtration and 52\% with HEPA filtration. The authors did not report the amount of time participants spent inside their homes. Air filtration was associated with significant reductions in systolic blood pressure and marginally significant reductions in diastolic blood pressure. In Beijing, Zhan et al. [61] found that $48 \mathrm{~h}$ of portable HEPA filtration in six residences reduced average bedroom $\mathrm{PM}_{2.5}$ concentrations from 49 to $9 \mu \mathrm{g} / \mathrm{m}^{3}$, but average personal exposure was higher during filtration. The authors attributed the lack of exposure reductions to time spent in other microenvironments. A crossover study of 43 children near Shanghai indicated that 2 weeks of bedroom HEPA filtration reduced average indoor $\mathrm{PM}_{2.5}$ concentrations by $68 \%$ but reduced average personal exposure by only $27 \%$. Although the children's time- activity patterns were not reported, the authors attributed the more modest reductions in personal exposure to time spent in other locations [62].

Three recent studies suggest that the economic benefits of filtration would often exceed purchase and operation costs, particularly if the filtration is targeted to susceptible subpopulations [63, 64•, 65]. Fisk and Chan [63] modeled the impacts of portable and HVAC air filter use for 10 days during the 2003 southern California wildfires. When used in all homes, the economic benefits of reduced mortality outweighed costs for HVAC filtration, but not for portable air purifiers. However, both interventions were more cost effective when targeted elderly residents, a group at elevated risk of mortality during fire smoke events. In a second study, these authors quantified the costs and economic benefits of reduced particle-related mortality from long-term user of portable and HVAC filtration in US homes and workplaces [64•]. Benefits exceeded costs in all scenarios, with cost-benefit ratios ranging from 3.9 to 133 . Investigators in Detroit modeled the impact of enhanced HVAC filtration in homes and schools on exposure to outdoor-generated PM and asthma-related outcomes [65]. They found that installing enhanced filters in schools would be cost effective, while enhanced filters in homes of asthmatic children would be more expensive and less cost effective. These studies probably underestimated total benefits because they focused on a narrow range of health outcomes and only considered the impacts of outdoorgenerated pollution.

Finally, three recent studies reported potentially determinantal effects from other air purifier technologies. In China's Hunan province, removal of HEPA filters from HVAC systems in offices and dormitories led to large increases in $\mathrm{PM}_{2.5}$ concentrations but did not alter biomarkers of cardiopulmonary risk among 89 young adults [66]. But removal of EPs from HVAC systems led to small decreases in ozone concentrations and several cardiovascular risk biomarkers, indicating potential adverse effects from ozone produced by EPs. In Beijing, Liu and colleagues [67 ${ }^{\circ}$ conducted a randomized crossover study of IGs in the dormitories of 56 healthy university students. One week of IG use reduced indoor $\mathrm{PM}_{2.5}$ concentrations but increased negative ion concentrations. Negative ions were associated with an increase in malondialdehyde, a biomarker of systemic oxidative stress, which offset the benefits of $\mathrm{PM}_{2.5}$ reductions resulting in no net effect of IG use on malondialdehyde. There were also no effects of IG use on measures of lung function, vascular tone, arterial stiffness, or inflammation. In a similar study of 44 children in Beijing classrooms, Dong et al. [68] reported that 5 days of IG use decreased $\mathrm{PM}_{2.5}$ and $\mathrm{BC}$, improved lung function and reduced airway inflammation, but did not alter blood pressure. However, the study also found that negative ions were associated with detrimental effects on HRV. 


\section{Facemasks}

Unlike air purifiers, facemasks have the potential to reduce exposure in multiple indoor and outdoor locations. We use the term "facemask" to include a range of materials worn on the face including improvised masks (t-shirts, handkerchiefs, bandanas, etc.) [69], procedure or surgical masks, and air purifying respirators designed for occupational settings [70].

Occupational health and safety organizations typically evaluate and certify respirators used in workplaces [71]. For example, in the USA, the National Institute for Occupational Safety and Health categorizes particlefiltering respirators by three categories of oil resistance and three levels of efficiency $(95,99$, and $99.97 \%)$ at removing $0.3 \mu \mathrm{m}$ particles [71]. The most common of these is the N95 (or equivalent, e.g., FFP2 in Europe and KN95 in China) [72]. Facemask effectiveness is governed by both the material's filtration efficiency and the mask's facial fit, and in workplaces respirators are typically fit tested on workers. In contrast, respirators marketed for use in community settings do not typically undergo testing or certification. The costs of facemasks vary widely. Typical costs for procedure masks and N95 respirators are $<\$ 0.50$ US and \$2 US, respectively, while reusable respirators marketed for protection against community air pollution can cost up to $\$ 50$ US.

To our knowledge, only two studies published prior to 2017 evaluated the health benefits of facemask use in community settings [73, 74]. Both were conducted in Beijing and provided evidence that short-term use of N95 respirators can reduce the effects of air pollution on blood pressure and HRV. Recent studies have added to this limited literature on health impacts, while others evaluated the exposure benefits of a broader range of facemask materials and designs.

Since 2017, three additional studies of N95 masks and health outcomes have been published. In Shanghai, Shi and colleagues [75] conducted a randomized crossover trial in which 24 healthy young adults wore N95 respirators during one of two 48-h periods. Participants were instructed on how to wear respirators to achieve a good fit. Respirator use was associated with reduced mean systolic blood pressure and improved HRV. Yang and colleagues [76] performed a randomized crossover study in Beijing's subway system to evaluate short-term cardiovascular benefits from both respirators and noise-canceling headphones. Participants underwent extensive respirator fit testing. Both interventions were associated with improved HRV and decreased heart rate, but there were no associations with blood pressure. Most recently, Guan and collaborators [77•] studied the influence of N95 masks on airway inflammation and endothelial function among 15 healthy young volunteers in Beijing. The notable difference from previous work was the double-blind design with sham facemasks (facemasks with filters removed). The authors did not provide information on fit testing. After participants walked a defined route along a busy road for $2 \mathrm{~h}$ while wearing a facemask, the investigators measured health outcomes four times over a 24 -h period. The procedure was repeated 1 month later using the opposite mask configuration. Compared with sham facemasks, the real facemasks attenuated pollution-induced effects on airway inflammation. There were no effects on systemic oxidative stress, and one arterial stiffness indicator was significantly elevated after participants wore the real facemasks. This may have been due to facemasks increasing respiration resistance or inducing deeper breathing leading to changes in airway deposition.

Several other recent studies of facemasks evaluated the exposure reduction potential of various facemask materials and designs. Two studies used mannequins and two enrolled human volunteers, but all emphasized the importance of facial fit on performance. Using a mannequin, Shakya and colleagues [78] found that cloth masks filtered 15 to $57 \%$ of diesel particles. A surgical mask had 79\% efficiency, similar to the N95 masks tested. The authors noted that the best performing cloth mask conformed to the mannequin's contours while the less effective cloth masks did not provide a good fit. Pacitto et al. [79•] studied nine facemasks available in Spain at prices ranging from 1 to 44 Euros (approximately $\$ 1.10$ to $\$ 50$ US). Mask effectiveness in removing $\mathrm{PM}_{2.5}$ ranged from 14 to $96 \%$, with lower effectiveness for black carbon and particle number count. The authors noted that mask costs were related more closely to esthetics than effectiveness.

Cherrie and colleagues [26] evaluated particle penetration through nine facemasks that are commercially available in China, then selected four masks for additional testing on human volunteers. A key finding was that despite being made of highly efficient particle-filtering materials, two of the four masks performed poorly during human volunteer testing because of inadequate fit. A similar study evaluated 17 facemasks - ranging in sophistication from improvised masks to an N99 mask-used for protection against volcanic ash, which is composed of larger and more easily filtered particles than urban air [69]. Certified masks (N95 and N99) performed best (filtration efficiencies $>98 \%$ ), followed by surgical masks $(89-91 \%)$ and improvised mask materials $(<44 \%)$. Four of the masksincluding an N95 respirator, a surgical mask designed to filter $\mathrm{PM}_{2.5}$, a standard surgical mask, and a basic "flat fold" dust mask - were then tested on human volunteers for quantification of total inward leakage (TIL) [80]. The TIL of the N95 mask was 9\%, compared with 22 to $35 \%$ for the other masks. Study participants rated the N95 as the most protective due to sturdiness and fit, but also as uncomfortable and difficult to breathe through. 


\section{Behavior Modifications}

\section{Staying Indoors and Closing Windows}

Air pollution dose is influenced by concentration and breathing rate, so changing locations and activities may be beneficial [33]. During pollution episodes, government and public health agencies often recommend reducing outdoor activities, particularly for susceptible groups [81, 82].

The level of protection provided by residences and other buildings varies depending on window opening, air conditioning use, use of air purifiers, building age and condition, and other factors. In seven US communities, we found mean $\mathrm{PM}_{2.5}$ infiltration efficiencies $\left(F_{\text {inf }}\right.$, the fraction of outdoor $\mathrm{PM}_{2.5}$ concentration that penetrates indoors and remains suspended) ranging from 0.49 to 0.74 in the heating season and 0.43-0.90 in the non-heating season [46]. Several recent studies in Chinese cities estimated mean $F_{\text {inf }}$ in the heating and non-heating seasons of $0.54-0.79$ and $0.70-0.91$, respectively [83-85].

To our knowledge, only two studies - both conducted in Taipei-directly evaluated the health benefits of keeping windows closed and both were published prior to 2017. In a 2009 study, 40 healthy university students underwent hourly blood pressure and heart rate measurements during four 48-h monitoring sessions [86]. The researchers asked participants to stay home and keep gas stoves turned off, and to keep windows open during the first two measurements and closed during the last two measurements. Indoor $\mathrm{PM}_{2.5}$ concentrations, blood pressures, and heart rates were higher when windows were open than when windows were closed. The same researchers later enrolled 300 healthy adults and compared three exposure conditions: windows open, windows closed without air conditioning, and windows closed with air conditioning [87]. Closing windows had little effect on $\mathrm{PM}_{2.5}$ concentrations, but levels were $44 \%$ lower when air conditioning was used (26 vs $14 \mu \mathrm{g} / \mathrm{m}^{3}$ ). HRV improved both when windows were closed and when air conditioning was turned on, while oxidative stress and systemic inflammation markers decreased only when air conditioners were turned on. Unfortunately, the investigators did not randomize treatment order or report outdoor PM concentrations.

In a 2019 study, Reisen and colleagues [88] reported measurements of outdoor and indoor $\mathrm{PM}_{2.5}$ concentrations at 21 residences in Australian community impacted by smoke from prescribed burns and bushfires. Seven of the homes were monitored during smoke plume events. There were no personal exposure measurements. Residents completed a diary on indoor pollution source activities and window opening. The authors found that during smoke plume events hourly peak $\mathrm{PM}_{2.5}$ concentrations were reduced by 12 to $76 \%$ when windows and doors were closed. But the authors also reported that leaving windows closed after a smoke event had ended trapped $\mathrm{PM}_{25}$ indoors and increased indoor concentrations.

The potential protection provided by buildings must be balanced with other factors including indoor pollution sources [89], heat [90], and impacts on physical activity [91•]. A 2018 study in Beijing estimated that increasing building air-tightness, without adding mechanical ventilation and/or filtration, would reduce the infiltration of outdoor pollution but amplify the impact of indoor emissions, leading to higher indoor $\mathrm{PM}_{2.5}$ concentrations [89].

\section{Travel Modes and Routes}

Travel can disproportionately impact exposure to trafficrelated air pollution (TRAP) $[92,93]$. TRAP concentrations are highly variable and several cities have online tools to help commuters select routes with less air pollution. Travel mode can also be important because it influences travel route and duration, breathing rate, and the degree of protection from ambient pollution.

Three review papers published in 2017 or 2018 concluded that, compared to active commuters, drivers generally encountered higher concentrations of TRAP [91, 94, 95]. However, active commuters often had higher inhaled doses due to increased minute ventilation and longer trip durations $[91 \bullet, 95]$. Incorporating the benefits of physical activity, Cepeda and colleagues [91•] found that median life expectancy losses were up to 1 year lower among active commuters, indicating that the benefits outweighed the negative effects of pollution.

There were several randomized crossover studies of route and cardiopulmonary health published prior to 2017. Results from studies of cyclists were mixed [96-99], while a study of individuals with asthma in London found that walking for $2 \mathrm{~h}$ on Oxford Street induced greater reductions in lung function than walking in Hyde Park, where pollution levels were lower [100].

Our review identified three recent crossover studies of travel routes and health in addition to several recent studies of exposure. Participants in London aged 60 years and older walked for $2 \mathrm{~h}$ either along Oxford Street or in Hyde Park, then in the opposite location 3 to 8 weeks later [101]. Personal exposures to TRAP and noise were significantly higher on Oxford Street. Walking in Hyde Park led to improvements in several cardiopulmonary markers, while walking on Oxford Street was less beneficial. In a study of 32 healthy adult cyclists in Sacramento, Park and colleagues [102] asked participants to complete one ride each on a low- and hightraffic route. UFP concentrations were nearly three times higher on the high-traffic route. Lung function measures improved while cycling on the low-traffic route and either decreased or were unchanged during the high-traffic ride. Unfortunately, the specific routes were not uniform across participants and the authors did not indicate whether route order was randomly assigned. In Vancouver, Cole et al. 
[103] conducted a randomized crossover study in which 38 adults cycled for $1 \mathrm{~h}$ on both a downtown and residential route. Median exposures to $\mathrm{PM}_{2.5}$ and UFP were $30 \%$ and $53 \%$ higher, respectively, on the downtown route. Reactive hyperemia index (RHI, a measure of endothelial function) decreased after cycling downtown and increased after cycling in the residential area. But changes in RHI were not associated with air pollutants and the authors speculated that the differences between routes may have been due to other exposures such as physical exertion, noise, or stress. Other measures of lung function, systemic inflammation, and oxidative stress were not associated with route.

Several other recent studies reported on the effect of route on TRAP exposure only, with most focused on cyclists. These studies consistently found routes with less vehicle traffic were associated with lower BC concentrations, with less consistent evidence of reductions in UFP or $\mathrm{PM}_{2.5}$ [104-110]. A study in Fort Collins, Colorado, a city with relatively low levels of air pollution, also found that by selecting an alternative route drivers significantly reduced cumulative exposures to $\mathrm{BC}$ and carbon monoxide by $15 \%$, but $\mathrm{PM}_{2.5}$ exposures were unchanged [110].

\section{Vehicle Ventilation and Filtration}

By 2017, there was substantial evidence that in-vehicle concentrations of UFP and other traffic-related particles are influenced by opening windows, recirculating cabin air, and/or the use of enhanced filtration [111-115]. These findings have been reinforced by recent studies, some of which documented considerable variation in particle concentrations under different ventilation conditions [115-117]. For example, Kumar and colleagues [117] drove pre-planned routes in 10 cities and measured in-vehicle $\mathrm{PM}_{2.5}$ concentrations with windows open and fan off (windows open), windows closed with fan on (fan on), and windows closed with recirculation mode on (recirculation). Relative to recirculation mode, $\mathrm{PM}_{2.5}$ concentrations were up to $385 \%$ higher with fan on and up to $1020 \%$ higher with windows open.

In contrast, the evidence that vehicle ventilation or filtration influence health is much more limited. Prior to 2017, we are aware of one study that directly addressed this issue. In that non-randomized study, the use of a vehicle's air conditioning system improved air quality and modified the effects of $\mathrm{PM}_{2.5}$ on HRV [118]. More recently, in a non-randomized study, Yu and colleagues [119, 120] found that using high-efficiency cabin air filters in taxis with windows closed reduced mean $\mathrm{PM}_{2.5}$ and ultrafine concentrations by $37 \%$ and $47 \%$, respectively, but did not alter oxidative stress indicators.

That study and several others published recently also emphasized the trade-offs between closing windows and recirculating cabin air to reduce particle concentrations and avoiding high levels of $\mathrm{CO}_{2}$, which can cause drowsiness and cognitive impairment [115, 120-125]. Hudda and Fruin [125] conducted a modeling study to identify vehicle and trip characteristics associated with elevated $\mathrm{CO}_{2}$ concentrations in passenger vehicles. They concluded that most one- or twooccupant trips of average duration would not exceed $2500 \mathrm{ppm}$ (ppm) of $\mathrm{CO}_{2}$, a threshold that has consistently been found to impair mental performance. However, for multiple passenger or long-distance trips, the authors suggested that recirculation mode should be periodically interrupted to avoid having $\mathrm{CO}_{2}$ concentrations exceed 2500 ppm.

\section{Discussion}

The peer-reviewed literature on individual- and householdlevel interventions has expanded considerably in recent years. There is compelling evidence from randomized studies that HEPA filter air purifier use over days or weeks can reduce $\mathrm{PM}_{2.5}$ concentrations and improve subclinical cardiopulmonary health. There have been fewer studies of facemask use in non-occupational settings, but there is evidence that wellfitting N95 respirators can reduce $\mathrm{PM}_{2.5}$ exposure, with several randomized crossover studies also indicating that shortterm use improves subclinical cardiovascular health. The effectiveness of other types of masks and face coverings in reducing exposure is highly variable, depends largely on fit, and is unrelated to cost. At present, there is no direct evidence that these masks provide health benefits. Some behaviorssuch as traveling on less polluted routes, driving with windows closed, or using enhanced vehicle filtration-may reduce exposure, but there is little evidence that these changes benefit health.

Despite their potential benefits, these interventions all have limitations. For example, portable air filters may be prohibitively expensive for some families. In our studies, some participants expressed concern about electricity costs and noise [58•]. In addition, air filters are less effective at higher air exchange rates [58•] or for individuals who spend time in other locations [60-62]. In some studies, participants were asked to stay indoors, keep windows closed, or use air filters continuously, so published results may represent best case scenarios $[57 \bullet, 61,62]$. The benefits of reduced $\mathrm{PM}_{2.5}$ concentrations from electrostatic precipitators and negative ion generators may be offset by the harmful effects of ozone and negative ions, respectively $[67 \bullet, 68]$. Respirators designed for occupational use may be unavailable or prohibitively expensive in some settings [69, 126•], a good facemask fit may be unachievable for children and some adults [127-129], and a poor fitting facemask may give a false sense of security [38]. Higher efficiency masks, such as N95, can be uncomfortable and may make breathing difficult $[77 \bullet, 80]$. This may be particularly problematic for those with compromised cardiorespiratory health, a group that is vulnerable to air pollution and 
therefore among the most likely to benefit from exposure reductions [41, 42]. Masks marketed for use in community settings are not subject to testing or certification, and mask cost does not predict effectiveness [79•]. Staying indoors and closing windows may be less effective without air conditioning [87], may amplify the impact of indoor emissions [89], and must be weighed against other hazards such as heat and decreased physical activity $[90,91 \bullet, 130]$. The viability of alternate route selection as an exposure mitigation strategy for active commuters, particularly pedestrians, may be limited if the lower exposure route substantially increases the journey distance [131, 132]. Recirculating cabin air in vehicles can elevate $\mathrm{CO}_{2}$ concentrations, particularly on multi-passenger and/or long trips [125].

Our review identified several gaps in the literature. With few exceptions, researchers evaluated IHL intervention use over short durations and measured only subclinical health endpoints. We support calls for studies of long-term use and clinically relevant outcomes [133, 134]. In addition, little is currently known about the long-term developmental impacts from use of these interventions by pregnant women. In our UGAAR birth cohort study, we found that portable air purifier use improved fetal growth [59•], and we are currently investigating whether exposure reductions during pregnancy alter developmental trajectories and provide benefits that extend into childhood [135]. There is anecdotal evidence that N95 and equivalent masks are often unavailable in the most polluted locations, so we recommend health studies of the face coverings that are available and used in those settings. In addition, while a small number of studies evaluated comfort and "wearability" of facemasks among children [128, 129], we are unaware of any studies of the exposure or health benefits of facemask use among children in community settings. The standard advice during pollution episodes is to remain indoors and reduce outdoor activities. This advice is largely based on studies showing that infiltration efficiencies for outdoor $\mathrm{PM}_{2.5}$ and other pollutants are $<1$. But there is surprisingly little direct evidence that these behavior changes provide any benefits. Thus, there is a need for carefully designed studies to evaluate the effectiveness of this routinely suggested behavior change, particularly for health. We recommend the use of randomized designs when feasible, but researchers will need to carefully consider the inherent ethical challenges [136]. For example, as evidence of air purifier effectiveness continues to accumulate, it may become unethical to withhold them from control participants in randomized studies.

A common criticism of IHL interventions is that they shift the burden of environmental protection from governments to individuals [126•]. Polluting industries may also promote these interventions to avoid or delay government regulations. For example, we question the motives of a Mongolian coal company that has promoted the use of facemasks in Ulaanbaatar. We strongly agree that governments are responsible for air quality management, and IHL interventions can never replace sound environmental and public health policies that address emissions over the long term [126•]. However, when evaluating the merits of these interventions, one should consider that $90 \%$ of the world's population breathes pollution above the WHO guideline concentration [1] and that, historically, policy-driven improvements in air quality took decades [8]. Given this slow grind toward clean air, and the ubiquity of the problem, it is unsurprising that individuals try to protect themselves. In addition, some sources of air pollution - such as forest fires - cannot be directly controlled at the source so risks must be mitigated at the household level [136]. Climate change will increase the relative impact of forest fires on air quality [137], and an increasing number of agencies recommend the use of air purifiers during fire smoke events [138].

A second frequent criticism of these interventions is that they may exacerbate environmental injustice [126•]. However, this criticism assumes that the costs of these interventions are borne by users, which has typically been the case [139]. Air purifiers and facemasks could potentially be distributed by public health or environmental organizations in a way that reduces inequities. A recent study in Beijing suggested that air filtration can exacerbate or alleviate exposure inequities, depending on how filtration is used [140•]. $\mathrm{PM}_{2.5}$ concentrations in 97 city districts were inversely correlated with mean income and percentage of high school graduates, and the authors argued that governments should provide air purifiers in disadvantaged areas to reduce inequities. Numerous papers have discussed emissions reduction strategies to improve equity [141-143], but the potential for targeted IHL interventions to improve equity has received little attention.

We believe that the research community should rigorously evaluate these interventions so that public health officials can make evidence-based recommendations that enable the public to make informed choices. In addition, as we have described previously, randomized "intervention studies" do more than test interventions; these studies provide large exposure gradients with which to study exposure-health relationships, generate compelling evidence of causality, and provide results that are easily communicated [136].

\section{Conclusions}

There is now substantial evidence that HEPA filter air purifiers reduce indoor $\mathrm{PM}_{2.5}$ concentrations and improve subclinical cardiopulmonary health indicators. Several studies have also found subclinical cardiovascular health benefits from well-fitting respirators, while the exposure benefits of other facemasks is highly variable and health benefits have not been tested. Similarly, some behavior changes may reduce exposure but evidence of health benefits remains very limited. Risk 
mitigation at the household level may be the primary option when emissions cannot be controlled at the source, such as during forest fires, or in communities like Ulaanbaatar where acceptable air quality is seemingly many years away. In most cases, however, individual- and household-level interventions should be supplemental to government policies targeting pollution emissions that benefit entire communities.

\section{Compliance with Ethical Standards}

Conflict of Interest The air purifiers used in our UGAAR study were purchased at a discounted rate from the manufacturer, who also made minor modifications to the units at our request. The authors have no other conflicts of interest to disclose.

Human and Animal Rights and Informed Consent All procedures in cited studies conducted by the authors were in accordance with the ethical standards of Simon Fraser University, the Mongolian National University of Medical Sciences, and the Mongolian Ministry of Health.

Open Access This article is licensed under a Creative Commons Attribution 4.0 International License, which permits use, sharing, adaptation, distribution and reproduction in any medium or format, as long as you give appropriate credit to the original author(s) and the source, provide a link to the Creative Commons licence, and indicate if changes were made. The images or other third party material in this article are included in the article's Creative Commons licence, unless indicated otherwise in a credit line to the material. If material is not included in the article's Creative Commons licence and your intended use is not permitted by statutory regulation or exceeds the permitted use, you will need to obtain permission directly from the copyright holder. To view a copy of this licence, visit http://creativecommons.org/licenses/by/4.0/.

\section{References}

Papers of particular interest, published recently, have been highlighted as:

- Of importance

1. Health Effects Institute. State of Global Air 2019. Special Report. 2019. https://www.stateofglobalair.org/sites/default/files/soga 2019_report.pdf.

2. Pope CA, et al. Fine-particulate air pollution and life expectancy in the United States. N Engl J Med. 2009;360:376-86.

3. Samet JM. The clean air act and health - a clearer view from 2011. N Engl J Med. 2011;365:198-201. https://doi.org/10.1056/ nejmp1103332.

4. Schraufnagel DE, Balmes JR, de Matteis S, Hoffman B, Kim WJ, Perez-Padilla R, et al. Health benefits of air pollution reduction. Ann Am Thorac Soc. 2019;16:1478-87.

5. Burnett R, Chen H, Szyszkowicz M, Fann N, Hubbell B, Pope CA III, et al. Global estimates of mortality associated with long-term exposure to outdoor fine particulate matter. Proc Natl Acad Sci. 2018;115:9592-7.

6. Crouse DL, Peters PA, van Donkelaar A, Goldberg MS, Villeneuve PJ, Brion O, et al. Risk of nonaccidental and cardiovascular mortality in relation to long-term exposure to low concentrations of fine particulate matter: a Canadian nationallevel cohort study. Environ Health Perspect. 2012;120:708-14.

7. Pinault L, et al. Risk estimates of mortality attributed to low concentrations of ambient fine particulate matter in the Canadian community health survey cohort. Environ Heal A Glob Access Sci Sour. 2016;15.

8. Fenger J. Urban air quality. Atmos Environ. 1999;33:4877-900.

9. Chen Z, Wang J-N, Ma G-X, Zhang Y-S. China tackles the health effects of air pollution. Lancet. 2013;382:1959-60. https://doi.org/ 10.1016/s0140-6736(13)62064-4.

10. Huang J, Pan X, Guo X, Li G. Health impact of China's air pollution prevention and control action plan: an analysis of national air quality monitoring and mortality data. Lancet Planet Heal. 2018;2:e313-23. https://doi.org/10.1016/S2542-5196(18)30141-4.

11. Zhang Q, et al. Drivers of improved PM2.5 air quality in China from 2013 to 2017. Proc Natl Acad Sci U S A. 2019. https://doi. org/10.1073/pnas.1907956116.

12. Allen RW, Gombojav E, Barkhasragchaa B, Byambaa T, Lkhasuren $\mathrm{O}$, Amram $\mathrm{O}$, et al. An assessment of air pollution and its attributable mortality in Ulaanbaatar, Mongolia. Air Qual Atmos Health. 2013;6:137-50.

13. Ross E. How deadly pollution became one of Mongolia's biggest problems. Newsweek. 2017. https://www.newsweek.com/ pollution-mongolia-ulaanbaatar-deadly-kill-children-higherbeijing-562881. Accessed 4 March 2019.

14. Hincks J. Life in the most polluted capital in the world. TIME. 2018. https://time.com/longform/ulan-bator-mongolia-mostpolluted-capital/. Accessed 4 March 2019.

15. Denton B. Burning coal for survival in the world's coldest capital. The New York Times; 2018. https://www.nytimes.com/ interactive/2018/03/15/world/asia/mongolia-ulan-bator-coal.html. Accessed 4 March 2019.

16. Kuo L., Davaasharav M. Pollution pushes Mongolia's herders to reconsider city life. 2018. https://www.theguardian.com/world/ 2018/sep/24/pollution-pushes-mongolias-herders-to-reconsidercity-life. Accessed 4 March 2019.

17. Brown G. In frigid cold, Mongolians stand in protest of air pollution. The Washington Post; 2017. https://www.washingtonpost. com/world/in-frigid-cold-mongolians-stand-in-protest-of-airpollution/2017/01/28/1a9df486-e5a4-11e6-a547-5fb9411d332c story.html. Accessed 21 March 2019.

18. Hill LD, et al. Health assessment of future PM2.5exposures from indoor, outdoor, and secondhand tobacco smoke concentrations under alternative policy pathways in Ulaanbaatar, Mongolia. PLoS One. 2017;12:1-26.

19. Ban J, Zhou L, Zhang Y, Brooke Anderson G, Li T. The health policy implications of individual adaptive behavior responses to smog pollution in urban China. Environ Int. 2017;106:144-52.

20. Xiong L, et al. Risk reduction behaviors regarding PM 2.5 exposure among outdoor exercisers in the Nanjing metropolitan area, China. Int J Environ Res Public Health. 2018;15:1-13.

21. Wong LP, Alias H, Aghamohammadi N, Ghadimi A, Sulaiman NMN. Control measures and health effects of air pollution: a survey among public transportation commuters in Malaysia. Sustain. 2017;9.

22. Bayasgalan O. https://www.indiegogo.com/projects/100-airpurifiers-to-reduce-pollution-mortalities\%2D\%2D2\#/. Accessed 11 Feb 2020.

23. Slater J. India's pollution refugees: people are fleeing Delhi because of the toxic air. Washington Post; 2018. https://www. washingtonpost.com/world/asia_pacific/indias-pollutionrefugees-people-are-fleeing-delhi-because-of-the-smoggy-air/ 2018/11/15/26dc1250-e1f1-11e8-a1c9-6afe99dddd92_story. html. Accessed 11 Feb 2020.

24. Demick B. Businesses cashing in on China's air pollution. Seattle Times; 2013. https://www.seattletimes.com/nation-world/ 
businesses-cashing-in-on-chinarsquos-air-pollution/. Accessed 22 March 2019.

25. Li G. China's face mask industry under scrutiny as pollution worsens. Reuters; 2014. https://www.reuters.com/article/uschina-mask-pollution/chinas-face-mask-industry-under-scrutinyas-pollution-worsens-idUSBREA2O0GI20140325. Accessed 22 Mar 2019.

26. Cherrie JW, Apsley A, Cowie H, Steinle S, Mueller W, Lin C, et al. Effectiveness of face masks used to protect Beijing residents against particulate air pollution. Occup Environ Med. 2018;75: 446-52.

27. Smart Air. https://smartairfilters.com/cn/en/. Accessed 22 March 2019.

28. Brizi. https://www.brizi.com/. Accessed 1 April 2019.

29. LeTrent S. Unmasking a new trend: stylish smog masks. CNN; 2014. http://www.cnn.com/2014/10/31/living/smog-mask-chinafashion-week/index.html. Accessed 22 March 2019.

30. Ellis-Peterson H. Five million pollution masks to be handed to Delhi residents. The Guardian; 2019. https://www.theguardian. com/world/2019/nov/02/five-million-pollution-masks-to-behanded-to-delhi-residents. Accessed 11 Feb 2020.

31. Liu T, He G, Lau A. Avoidance behavior against air pollution: evidence from online search indices for anti-PM 2.5 masks and air filters in Chinese cities. Environ Econ Policy Stud. 2018;20:32563.

32. Zhang J, Mu Q. Air pollution and defensive expenditures: evidence from particulate-filtering facemasks. J Environ Econ Manag. 2018;92:517-36.

33. Giles LV, Barn P, Künzli N, Romieu I, Mittleman MA, van Eeden $\mathrm{S}$, et al. From good intentions to proven interventions: effectiveness of actions to reduce the health impacts of air pollution. Environ Health Perspect. 2011;119:29-36.

34. Zhang S, Li L, Gao W, Wang Y, Yao X. Interventions to reduce individual exposure of elderly individuals and children to haze: a review. J Thorac Dis. 2016;8:E62-8.

35. Laumbach $\mathrm{R}$, Meng Q, Kipen $\mathrm{H}$. What can individuals do to reduce personal health risks from air pollution? J. Thorac. Dis. 2015;7:96-107.

36. Kelly FJ, Fussell JC. Improving indoor air quality, health and performance within environments where people live, travel, learn and work. Atmos Environ. 2019;200:90-109 A comprehensive review of air purification and ventilation in homes, schools, workplaces, and vehicles.

37. Morishita M, Thompson KC, Brook RD. Understanding air pollution and cardiovascular diseases: is it preventable? Curr Cardiovasc Risk Rep. 2015;9:1-9.

38. Bard RL, Ijaz MK, Zhang J(J), Li Y, Bai C, Yang Y, et al. Interventions to reduce personal exposures to air pollution: a primer for health care providers. Glob Heart. 2019;14:47-60.

39. Hadley MB, Baumgartner J, Vedanthan R. Developing a clinical approach to air pollution and cardiovascular health. Circulation. 2018;137:725-42.

40. Hooper LG, Kaufman JD. Ambient air pollution and clinical implications for susceptible populations. Ann Am Thorac Soc. 2018;15:S64-8.

41. Carlsten C, Salvi S, Wong GWK, Chung KF. Personal strategies to minimise effects of air pollution on respiratory health: advice for providers, patients and the public. Eur Respir J. 2020;55: 1902056. https://doi.org/10.1183/13993003.02056-2019.

42. Laumbach RJ. Clearing the air on personal interventions to reduce exposure to wildfire smoke. Ann Am Thorac Soc. 2019;16:815-8. https://doi.org/10.1513/AnnalsATS.201812-894PS.

43. Quansah R, Semple S, Ochieng CA, Juvekar S, Armah FA, Luginaah I, et al. Effectiveness of interventions to reduce household air pollution and/or improve health in homes using solid fuel in low-and-middle income countries: a systematic review and meta-analysis. Environ Int. 2017;103:73-90. https://doi.org/10. 1016/j.envint.2017.03.010.

44. Noonan CW, et al. Wood stove interventions and child respiratory infections in rural communities: KidsAir rationale and methods. 2020;89:105909.

45. Leech JA, Nelson WC, Burnett RT, Aaron S, Raizenne ME. It's about time: a comparison of Canadian and American time-activity patterns. J Expo Anal Environ Epidemiol. 2002;12:427-32. https://doi.org/10.1038/sj.jea.7500244.

46. Allen RW, et al. Modeling the residential infiltration of outdoor PM2.5 in the multi-ethnic study of atherosclerosis and air pollution (MESA Air). Environ Health Perspect. 2012;824:824-30.

47. Azimi P, Stephens B. A framework for estimating the US mortality burden of fine particulate matter exposure attributable to indoor and outdoor microenvironments. J Expo Sci Environ Epidemiol. 2018;30:271-84. https://doi.org/10.1038/s41370-018-0103-4.

48. Xiang J, Weschler CJ, Wang Q, Zhang L, Mo J, Ma R, et al. Reducing indoor levels of "outdoor PM 2.5" in urban China: impact on mortalities. Environ Sci Technol. 2019;53:3119-27.

49. Walzer D, Gordon T, Thorpe L, Thurston G, Xia Y, Zhong H, et al. Effects of home particulate air filtration on blood pressure: a systematic review. Hypertension. 2020;76:44-50. https://doi.org/ 10.1161/HYPERTENSIONAHA.119.14456.

50. Bräuner EV, Forchhammer L, Møller P, Barregard L, Gunnarsen $\mathrm{L}, \mathrm{Afshari} \mathrm{A}$, et al. Indoor particles affect vascular function in the aged: an air filtration-based intervention study. Am J Respir Crit Care Med. 2008;177:419-25.

51. Allen RW, Carlsten C, Karlen B, Leckie S, Eeden S, Vedal S, et al. An air filter intervention study of endothelial function among healthy adults in a woodsmoke-impacted community. Am J Respir Crit Care Med. 2011;183:1222-30.

52. Chen R, Zhao A, Chen H, Zhao Z, Cai J, Wang C, et al. Cardiopulmonary benefits of reducing indoor particles of outdoor origin. J Am Coll Cardiol. 2015;65:2279-87. https://doi.org/10. 1016/j.jacc.2015.03.553.

53. Shao D, et al. Cardiorespiratory responses of air filtration: a randomized crossover intervention trial in seniors living in Beijing: Beijing Indoor Air Purifier StudY, BIAPSY. Sci Total Environ. 2017;603-604:541-9.

54. Liu S, Chen J, Zhao Q, Song X, Shao D, Meliefste K, et al. Cardiovascular benefits of short-term indoor air filtration intervention in elderly living in Beijing: an extended analysis of BIAPSY study. Environ Res. 2018;167:632-8.

55. Cui X, Li F, Xiang J, Fang L, Chung MK, Day DB, et al. Cardiopulmonary effects of overnight indoor air filtration in healthy non-smoking adults: a double-blind randomized crossover study. Environ Int. 2018;114:27-36.

56. Li H, Cai J, Chen R, Zhao Z, Ying Z, Wang L, et al. Particulate matter exposure and stress hormone levels. Circulation. 2017;136: 618-27.

57. Chuang HC, et al. Long-term indoor air conditioner filtration and cardiovascular health: a randomized crossover intervention study. Environ Int. 2017;106:91-6 One of the few studies to evaluate the benefits from long-term air filtration.

58. Barn P, et al. The effect of portable HEPA filter air cleaners on indoor PM2.5concentrations and second hand tobacco smoke exposure among pregnant women in Ulaanbaatar, Mongolia: The UGAAR randomized controlled trial. Sci Total Environ. 2018;615:1379-89.

59. Barn, P. K. et al. The effect of portable HEPA filter air cleaner use during pregnancy on fetal growth: the UGAAR randomized controlled trial. Environ. Int. in press, (2018). The only published study of air purifier use during pregnancy and fetal growth.

60. Morishita M, et al. Effect of portable air filtration systems on personal exposure to fine particulate matter and blood pressure 
among residents in a low-income senior facility a randomized clinical trial. 2018;178:1350-1357.

61. Zhan Y, Johnson K, Norris C, Shafer MM, Bergin MH, Zhang Y, et al. The influence of air cleaners on indoor particulate matter components and oxidative potential in residential households in Beijing. Sci Total Environ. 2018;626:507-18.

62. Barkjohn KK, et al. Real-time measurements of PM2.5 and ozone to assess the effectiveness of residential indoor air filtration in Shanghai homes. Indoor Air. 2020. https://doi.org/10.1111/ina. 12716.

63. Fisk WJ, Chan WR. Health benefits and costs of filtration interventions that reduce indoor exposure to PM2.5 during wildfires. Indoor Air. 2017;27:191-204.

64. Fisk WJ, Chan WR. Effectiveness and cost of reducing particlerelated mortality with particle filtration. Indoor Air. 2017;27:90920 This modeling analysis of particle filtration in US homes and commercial buildings estimated that economic benefits from reduced mortality would consistently exceed costs.

65. Martenies SE, Batterman SA. Effectiveness of using enhanced filters in schools and homes to reduce indoor exposures to PM 2.5 from outdoor sources and subsequent health benefits for children with asthma. Environ Sci Technol. 2018;52:10767-76.

66. Day DB, Xiang J, Mo J, Clyde MA, Weschler CJ, Li F, et al. Combined use of an electrostatic precipitator and a highefficiency particulate air filter in building ventilation systems: effects on cardiorespiratory health indicators in healthy adults. Indoor Air. 2018;28:360-72.

67. Liu W, et al. Negative ions offset cardiorespiratory benefits of PM 2.5 reduction from residential use of negative ion air purifiers. Indoor Air. 2020. https://doi.org/10.1111/ina.12728 Results from this study suggest that the health benefits of $\mathbf{P M}_{2.5}$ reductions from negative ion generators may be partly offset by negative effects from the ions.

68. Dong W, et al. Different cardiorespiratory effects of indoor air pollution intervention with ionization air purifier: findings from a randomized, double-blind crossover study among school children in Beijing. Environ Pollut. 2019. https://doi.org/10.1016/j. envpol.2019.113054.

69. Mueller W, Horwell CJ, Apsley A, Steinle S, McPherson S, Cherrie JW, et al. The effectiveness of respiratory protection worn by communities to protect from volcanic ash inhalation. Part I: Filtration efficiency tests. Int J Hyg Environ Health. 2018;221: 967-76

70. Doney BC, Groce DW, Campbell DL, Greskevitch MF, Hoffman WA, Middendorf PJ, et al. A survey of private sector respirator use in the United States: an overview of findings. J Occup Environ Hyg. 2005;2:267-76.

71. National Institute for Occupational Safety and Health. A Guide to Air-Purifying Respirators. 2018.

72. CDC National Personal Protective Technology Laboratory. NIOSH-Approved N95 Particulate Filtering Facepiece Respirators.

73. Langrish JP, et al. Beneficial cardiovascular effects of reducing exposure to particulate air pollution with a simple facemask. Part Fibre Toxicol. 2009;6:1-9.

74. Langrish JP, Li X, Wang S, Lee MMY, Barnes GD, Miller MR, et al. Reducing personal exposure to particulate air pollution improves cardiovascular health in patients with coronary heart disease. Environ Health Perspect. 2012;120:367-72.

75. Shi J, Lin Z, Chen R, Wang C, Yang C, Cai J, et al. Cardiovascular benefits of wearing particulate-filtering respirators: a randomized crossover trial. Environ Health Perspect. 2017;125:175-80.

76. Yang X, Jia X, Dong W, Wu S, Miller MR, Hu D, et al. Cardiovascular benefits of reducing personal exposure to trafficrelated noise and particulate air pollution: a randomized crossover study in the Beijing subway system. Indoor Air. 2018;28:777-86.
77. Guan T, et al. The effects of facemasks on airway inflammation and endothelial dysfunction in healthy young adults: a doubleblind, randomized, controlled crossover study. Part Fibre Toxicol. 2018;15:1-12 To our knowledge, this is the only double-blind study of the health benefits of facemasks.

78. Shakya KM, Noyes A, Kallin R, Peltier RE. Evaluating the efficacy of cloth facemasks in reducing particulate matter exposure. $\mathrm{J}$ Expo Sci Environ Epidemiol. 2017;27:352-7.

79. Pacitto A, et al. Effectiveness of commercial face masks to reduce personal PM exposure. Sci Total Environ. 2019;650:1582-90 This study evaluated nine facemasks that are commercially available in Spain and found that price is not indicative of mask effectiveness.

80. Steinle S, Sleeuwenhoek A, Mueller W, Horwell CJ, Apsley A, Davis A, et al. The effectiveness of respiratory protection worn by communities to protect from volcanic ash inhalation. Part II: Total inward leakage tests. Int J Hyg Environ Health. 2018;221:977-84.

81. D'Antoni D, Smith L, Auyeung V, Weinman J. Psychosocial and demographic predictors of adherence and non-adherence to health advice accompanying air quality warning systems: a systematic review. Environ Health A Glob Access Sci Sour. 2017;16:1-18.

82. Fish JA, Peters MDJ, Ramsey I, Sharplin G, Corsini N, Eckert M. Effectiveness of public health messaging and communication channels during smoke events: a rapid systematic review. J Environ Manag. 2017;193:247-56.

83. Li N, Liu Z, Li Y, Li N, Chartier R, McWilliams A, et al. Estimation of PM 2.5 infiltration factors and personal exposure factors in two megacities, China. Build Environ. 2019;149:297304.

84. Xu C, Li N, Yang Y, Li Y, Liu Z, Wang Q, et al. Investigation and modeling of the residential infiltration of fine particulate matter in Beijing, China. J Air Waste Manag Assoc. 2017;67:694-701.

85. Zhou X, Cai J, zhao Y, Chen R, Wang C, Zhao A, et al. Estimation of residential fine particulate matter infiltration in Shanghai, China. Environ Pollut. 2018;233:494-500.

86. Lin LY, Lin CY, Lin YC, Chuang KJ. The effects of indoor particles on blood pressure and heart rate among young adults in Taipei, Taiwan. Indoor Air. 2009;19:482-8.

87. Lin LY, Chuang HC, Liu IJ, Chen HW, Chuang KJ. Reducing indoor air pollution by air conditioning is associated with improvements in cardiovascular health among the general population. Sci Total Environ. 2013;463-464:176-81.

88. Reisen F, Powell JC, Dennekamp M, Johnston FH, Wheeler AJ. Is remaining indoors an effective way of reducing exposure to fine particulate matter during biomass burning events? J Air Waste Manag Assoc. 2019;69:611-22. https://doi.org/10.1080/ 10962247.2019.1567623.

89. Yuan Y, Luo Z, Liu J, Wang Y, Lin Y. Health and economic benefits of building ventilation interventions for reducing indoor PM 2.5 exposure from both indoor and outdoor origins in urban Beijing, China. Sci Total Environ. 2018;626:546-54.

90. Shaposhnikov D, Revich B, Bellander T, Bedada GB, Bottai M, Kharkova $\mathrm{T}$, et al. Mortality related to air pollution with the Moscow heat wave and wildfire of 2010. Epidemiology. 2014;25:359-64. https://doi.org/10.1097/EDE. 0000000000000090

91. Cepeda M, et al. Levels of ambient air pollution according to mode of transport: a systematic review. Lancet Public Health. 2017;2:e23-34 Review of air pollution concentrations by transportation mode. In addition to air pollution, the review also considered the physical activity benefits of active commuting.

92. Matz CJ, Stieb DM, Egyed M, Brion O, Johnson M. Evaluation of daily time spent in transportation and traffic-influenced microenvironments by urban Canadians. Air Qual Atmos Health. 2018;11: 209-20. https://doi.org/10.1007/s11869-017-0532-6. 
93. Fruin S, Westerdahl D, Sax T, Sioutas C, Fine PM. Measurements and predictors of on-road ultrafine particle concentrations and associated pollutants in Los Angeles. Atmos Environ. 2008;42:20719. https://doi.org/10.1016/j.atmosenv.2007.09.057.

94. de Nazelle A, Bode O, Orjuela JP. Comparison of air pollution exposures in active vs passive travel modes in European cities: a quantitative review. Environ Int. 2017;99:151-60.

95. Kumar P, Patton AP, Durant JL, Frey HC. A review of factors impacting exposure to PM2.5, ultrafine particles and black carbon in Asian transport microenvironments. Atmos Environ. 2018;187: 301-16.

96. Strak M, Boogaard H, Meliefste K, Oldenwening M, Zuurbier M, Brunekreef B, et al. Respiratory health effects of ultrafine and fine particle exposure in cyclists. Occup Environ Med. 2010;67:118 24. https://doi.org/10.1136/oem.2009.046847.

97. Weichenthal S, Kulka R, Dubeau A, Martin C, Wang D, Dales R. Traffic-related air pollution and acute changes in heart rate variability and respiratory function in urban cyclists. Environ Health Perspect. 2011;119:1373-8. https://doi.org/10.1289/ehp. 1003321.

98. Cole-Hunter T, Jayaratne R, Stewart I, Hadaway M, Morawska L, Solomon C. Utility of an alternative bicycle commute route of lower proximity to motorised traffic in decreasing exposure to ultra-fine particles, respiratory symptoms and airway inflammation - a structured exposure experiment. Environ Health A Glob Access Sci Sour. 2013. https://doi.org/10.1186/1476-069X-12-29.

99. Jarjour S, Jerrett M, Westerdahl D, de Nazelle A, Hanning C, Daly $\mathrm{L}$, et al. Cyclist route choice, traffic-related air pollution, and lung function: a scripted exposure study. Environ Health A Glob Access Sci Sour. 2013;12. https://doi.org/10.1186/1476-069X12-14.

100. McCreanor J, Cullinan P, Nieuwenhuijsen MJ, Stewart-Evans J, Malliarou E, Jarup L, et al. Respiratory effects of exposure to diesel traffic in persons with asthma. N Engl J Med. 2007;357: 2348-58. https://doi.org/10.1056/NEJMoa071535.

101. Sinharay R, Gong J, Barratt B, Ohman-Strickland P, Ernst S, Kelly FJ, et al. Respiratory and cardiovascular responses to walking down a traffic-polluted road compared with walking in a traffic-free area in participants aged 60 years and older with chronic lung or heart disease and age-matched healthy controls: a randomised, crosso. Lancet. 2018;391:339-49.

102. Park HY, Gilbreath S, Barakatt E. Respiratory outcomes of ultrafine particulate matter (UFPM) as a surrogate measure of nearroadway exposures among bicyclists. Environ Health A Glob Access Sci Sour. 2017;16:6. https://doi.org/10.1186/s12940-0170212-x.

103. Cole CA, Carlsten C, Koehle M, Brauer M. Particulate matter exposure and health impacts of urban cyclists: a randomized crossover study. Environ Health A Glob Access Sci Sour. 2018;17:78. https://doi.org/10.1186/s12940-018-0424-8.

104. Lonati G, Ozgen S, Ripamonti G, Signorini S. Variability of black carbon and ultrafine particle concentration on urban bike routes in a mid-sized city in the Po Valley (northern Italy). Atmosphere (Basel). 2017;8.

105. Hofman J, Samson R, Joosen S, Blust R, Lenaerts S. Cyclist exposure to black carbon, ultrafine particles and heavy metals: an experimental study along two commuting routes near Antwerp. Belgium Environ Res. 2018;164:530-8.

106. Jereb B, et al. Exposure to black carbon during bicycle commuting-alternative route selection. Atmosphere (Basel). 2018;9.

107. Merritt AS, Georgellis A, Andersson N, Bero Bedada G, Bellander T, Johansson C. Personal exposure to black carbon in Stockholm, using different intra-urban transport modes. Sci Total Environ. 2019;674:279-87.
108. Brand VS, Kumar P, Damascena AS, Pritchard JP, Geurs KT, Andrade MF. Impact of route choice and period of the day on cyclists' exposure to black carbon in London, Rotterdam and São Paulo. J Transp Geogr. 2019;76:153-65.

109. Qiu Z, Wang W, Zheng J, Lv H. Exposure assessment of cyclists to UFP and PM on urban routes in Xi'an, China. Environ Pollut. 2019;250:241-50.

110. Good N, Mölter A, Ackerson C, Bachand A, Carpenter T, Clark ML, et al. The Fort Collins commuter study: impact of route type and transport mode on personal exposure to multiple air pollutants. J Expo Sci Environ Epidemiol. 2016;26:397-404.

111. Knibbs LD, Cole-Hunter T, Morawska L. A review of commuter exposure to ultrafine particles and its health effects. Atmos Environ. 2011;45:2611-22. https://doi.org/10.1016/j.atmosenv. 2011.02.065

112. Xu B, Chen X, Xiong J. Air quality inside motor vehicles' cabins: a review. Indoor Built Environ. 2018;27:452-65. https://doi.org/ 10.1177/1420326X16679217.

113. Xu B, Zhu Y. Investigation on lowering commuters' in-cabin exposure to ultrafine particles. Transp Res Part D Transp Environ. 2013;18:122-30. https://doi.org/10.1016/j.trd.2012.10. 005.

114. Lee ES, Zhu Y. Application of a high-efficiency cabin air filter for simultaneous mitigation of ultrafine particle and carbon dioxide exposures inside passenger vehicles. Environ Sci Technol. 2014: 140207112527005. https://doi.org/10.1021/es404952q.

115. Tong Z, Li Y, Westerdahl D, Adamkiewicz G, Spengler JD. Exploring the effects of ventilation practices in mitigating invehicle exposure to traffic-related air pollutants in China. Environ Int. 2019;127:773-84. https://doi.org/10.1016/j.envint. 2019.03.023

116. Leavey A, Reed N, Patel S, Bradley K, Kulkarni P, Biswas P. Comparing on-road real-time simultaneous in-cabin and outdoor particulate and gaseous concentrations for a range of ventilation scenarios. Atmos Environ. 2017;166:130-41. https://doi.org/10. 1016/j.atmosenv.2017.07.016.

117. Kumar P, Hama S, Thiago Nogueira RA, et al. In-car particulate matter exposure across ten global cities. Sci Total Environ. 2020.

118. Chuang HC, Lin LY, Hsu YW, Ma CM, Chuang KJ. In-car particles and cardiovascular health: an air conditioning-based intervention study. Sci Total Environ. 2013;452-453:309-13. https:// doi.org/10.1016/j.scitotenv.2013.02.097.

119. $\mathrm{Yu} \mathrm{N}$, et al. High efficiency cabin air filter in vehicles reduces drivers' roadway particulate matter exposures and associated lipid peroxidation. PLoS One. 2017;12:1-13.

120. Yu N, Shu S, Lin Y, Zhu Y. Assessing and reducing fine and ultrafine particles inside Los Angeles taxis. Atmos Environ. 2018;181:155-63.

121. Barnes NM, Ng T, Ma KK, Lai KM. In-cabin air quality during driving and engine idling in air-conditioned private vehicles in Hong Kong. Int J Environ Res Public Health. 2018;15. https:// doi.org/10.3390/ijerph15040611.

122. Moreno T, Pacitto A, Fernández A, Amato F, Marco E, Grimalt $\mathrm{JO}$, et al. Vehicle interior air quality conditions when travelling by taxi. Environ Res. 2019;172:529-42. https://doi.org/10.1016/j. envres.2019.02.042.

123. Jung HS, Grady ML, Victoroff T, Miller AL. Simultaneously reducing $\mathrm{CO} 2$ and particulate exposures via fractional recirculation of vehicle cabin air. Atmos Environ. 2017;160:77-88. https:// doi.org/10.1016/j.atmosenv.2017.04.014.

124. Chen RY, Ho KF, Chang TY, Hong GB, Liu CW, Chuang KJ. Invehicle carbon dioxide and adverse effects: an air filtration-based intervention study. Sci Total Environ. 2020;723:138047. https:// doi.org/10.1016/j.scitotenv.2020.138047.

125. Hudda N, Fruin SA. Carbon dioxide accumulation inside vehicles: the effect of ventilation and driving conditions. Sci Total Environ. 
2018;610-611:1448-56. https://doi.org/10.1016/j.scitotenv.2017. 08.105 .

126. Seltenrich N. The Forest and the trees: how population-level health protections sometimes fail the individual. Environ Health Perspect. 2017. https://doi.org/10.1289/ehp.125-A65 This article summarizes several important criticisms and ethical considerations related to addressing environmental risks at the individual level.

127. US Food \& Drug Administration. N95 Respirators, surgical masks, and face masks. https://www.fda.gov/medical-devices/ personal-protective-equipment-infection-control/n95-respiratorssurgical-masks-and-face-masks.

128. Goh DYT, Mun MW, Lee WLJ, Teoh OH, Rajgor DD. A randomised clinical trial to evaluate the safety, fit, comfort of a novel N95 mask in children. Sci Rep. 2019;9:18952. https://doi. org/10.1038/s41598-019-55451-w.

129. Smart NR, Horwel CJ, Smart TS, Galea KS. Assessment of the wearability of facemasks against air pollution in primary schoolaged children in London. Int J Environ Res Public Health. 2020. https://doi.org/10.3390/ijerph17113935.

130. Tainio M, et al. Can air pollution negate the health benefits of cycling and walking? Prev Med (Baltim). 2016. https://doi.org/ 10.1016/j.ypmed.2016.02.002.

131. Anowar S, Eluru N, Hatzopoulou M. Quantifying the value of a clean ride: how far would you bicycle to avoid exposure to trafficrelated air pollution? Transp Res Part A Policy Pract. 2017;105: 66-78. https://doi.org/10.1016/j.tra.2017.08.017.

132. Hankey S, Lindsey G, Marshall JD. Population-level exposure to particulate air pollution during active travel: planning for low-exposure, health-promoting cities. Environ Health Perspect. 2017;125:527-34. https://doi.org/10.1289/EHP442.

133. Brook RD, Rajagopalan S. 'Stressed' about air pollution: time for personal action. Circulation. 2017;136:628-31. https://doi.org/10. 1161/CIRCULATIONAHA.117.029688.

134. Brook RD, Newby DE, Rajagopalan S. The global threat of outdoor ambient air pollution to cardiovascular health: time for intervention. JAMA Cardiol. 2017;2:353-4. https://doi.org/10.1001/ jamacardio.2017.0032.

135. Grandjean P, Barouki R, Bellinger DC, Casteleyn L, Chadwick LH, Cordier S, et al. Life-long implications of developmental exposure to environmental stressors: new perspectives. Endocrinology. 2015;156:3408-15.
136. Allen RW, Barn PK, Lanphear BP. Randomized controlled trials in environmental health research: unethical or underutilized? PLoS Med. 2015;12:1-5.

137. Ford B, Val Martin M, Zelasky SE, Fischer EV, Anenberg SC, Heald CL, et al. Future fire impacts on smoke concentrations, visibility, and health in the contiguous United States. GeoHealth. 2018;2:229-47. https://doi.org/10.1029/2018gh000144.

138. Barn PK, Elliott CT, Allen RW, Kosatsky T, Rideout K, Henderson SB. Portable air cleaners should be at the forefront of the public health response to landscape fire smoke. Environ Health. 2016;15:116. https://doi.org/10.1186/s12940-016-01989.

139. Saks, N. When wildfire smoke invades, who should pay to clean indoor air? Washington post; 2018. https://www.washingtonpost. $\mathrm{com} /$ national/health-science/when-wildfire-smoke-invades-whoshould-pay-to-clean-indoor-air/2018/03/08/a1b34388-22b911e8-946c-9420060cb7bd_story.html. Accessed 11 Feb 2020.

140. Huang G, Zhou W, Qian Y, Fisher B. Breathing the same air? Socioeconomic disparities in PM2.5 exposure and the potential benefits from air filtration. Sci Total Environ. 2019;657:619-26 These authors propose that air purifiers could be distributed by governments in a way that reduces health inequities. This idea has not been widely discussed or debated in the literature.

141. Levy JI, Wilson AM, Zwack LM. Quantifying the efficiency and equity implications of power plant air pollution control strategies in the United States. Environ Health Perspect. 2007;115:743-50. https://doi.org/10.1289/ehp.9712.

142. Martenies SE, Milando CW, Batterman SA. Air pollutant strategies to reduce adverse health impacts and health inequalities: a quantitative assessment for Detroit, Michigan. Air Qual Atmos Health. 2018;11:409-22. https://doi.org/10.1007/s11869-0170543-3.

143. Nguyen NP, Marshall JD. Impact, efficiency, inequality, and injustice of urban air pollution: variability by emission location. Environ Res Lett. 2018;13. https://doi.org/10.1088/1748-9326/ aa9cb5.

Publisher's Note Springer Nature remains neutral with regard to jurisdictional claims in published maps and institutional affiliations. 